\title{
Impact of Logistics Development on Economic Growth: An Empirical Research from Guangdong Province in China
}

\author{
Xiaofei Li $\mathbb{D}^{1,2}$ and Fen Chen (iD $^{3}$ \\ ${ }^{1}$ Zhuhai Da Hengqin Science and Technology Development Co., Ltd., Zhuhai 519031, China \\ ${ }^{2}$ Hubei Key Laboratory of Applied Mathematics, Faculty of Mathematics and Statistics, Hubei University, Wuhan 430062, China \\ ${ }^{3}$ Hubei Financial Development and Financial Security Research Center, Hubei University of Economics, Wuhan 430025, China
}

Correspondence should be addressed to Fen Chen; 29149875@qq.com

Received 21 March 2021; Accepted 13 May 2021; Published 21 May 2021

Academic Editor: Wei Wang

Copyright (C) 2021 Xiaofei Li and Fen Chen. This is an open access article distributed under the Creative Commons Attribution License, which permits unrestricted use, distribution, and reproduction in any medium, provided the original work is properly cited.

\begin{abstract}
This paper evaluates the impact of the development of the logistics industry on economic growth based on panel data of 21 cities in Guangdong Province in China from 2007 to 2019. Using the overall entropy method, the comprehensive development index of the logistics industry is constructed to capture the performance of the logistics industry. On this basis, by using Moran's index, we measure the spatial agglomeration effect of the logistics industry. Furthermore, direct and spatial spillover effects are also obtained. The estimation results of the spatial Durbin model (SDM) reveal that the elasticity coefficient of the effect of the comprehensive development level of the logistics industry on economic growth is 0.2590 , which is significant at the $1 \%$ level. In addition, the coefficient of the direct effect of the logistics industry on local economic growth is 0.4074 , and the coefficient of the spatial spillover effect on the economic growth of the surrounding areas is 0.3596 , which are both significant at the $1 \%$ level. These results indicate that the development of the logistics industry can not only improve local economic growth but also promote the economic growth of the surrounding regions.
\end{abstract}

\section{Introduction}

The logistics industry, known as the artery of the national economy, is the basic industry and an important pillar to promote the development of the national economy. The logistics industry is the link and bridge between production and consumption and between urban and rural areas. The development of the logistics industry has important impacts on breaking the barriers between regions and linking social production and residents' consumption. Especially in recent years, with "Industry 4.0" and "Internet plus" booming and deepening gradually, the flow of goods has become more frequent, and new technologies are constantly applied in the logistics industry. Technological progress in the logistics industry also changes the mode of economic development and promotes the coordinated development of the regional economy. The smart logistics industry, which promotes the transformation of the logistics industry, has come into being.
As a future development direction of the logistics industry, the smart logistics industry has been highly valued by the government and enterprises. The State Council of China has issued "Made in China 2025" and "The efficient logistics implementation opinion of Internet plus." These two documents proposed that the smart logistics industry will be the force of industrial changes and economic development in China. In the future, China should accelerate the transformation development from the traditional logistics industry to the smart logistics industry. Furthermore, increasingly numerous logistics enterprises, such as Jingdong, Cainiao, Meituan, and Shunfeng, have begun to implement smart logistics. These enterprises use smart technology to improve their efficiency and expand their market share in the highly complex logistics market to increase their competitiveness. They have developed advanced smart service systems and platforms and built an ecological smart logistics supply chain. Some intelligent algorithms 
such as machine learning methods have been developed [1-3].

As is known, a complete smart logistic system consists of a supply group, a medial operator, and a demand group. The core is a platform operation center $[4,5]$. Logistics enterprises provide a large and complete platform infrastructure for the improvement of industrial efficiency. Especially with the development of e-commerce, the social demand for a variety of products is increasing. The demand for the establishment of a large-scale, smart logistics industry system is becoming increasingly stronger. As an important part of the smart logistics industry, transportation not only increases the income of logistics enterprises but also contributes to the reasonable flow of production factors between regions. The development of the transportation in a region means that the central city can transport production factors to the surrounding areas, which is conducive to reducing the production costs in the surrounding areas and promoting regional economic growth. In addition, in order to reduce the logistics and transportation costs, some cities have gradually realized cooperation with each other. They have continuously improved the technological level of the logistics industry by expanding the industrial scale within the region; building logistics infrastructure; establishing a regional logistics information platform; and improving the levels of science and technology, education, and culture to attract cross-regional investment and cooperation. To some extent, these efforts have strengthened regional economic exchange and expanded the market space, not only promoting regional economic growth but also producing spillover effects on the economic growth of the surrounding areas [6].

In order to maintain the healthy and sustainable development of the smart logistics industry, the State Council formally promulgated and implemented the Medium-LongTerm Plan for the Development of the Smart Logistics Industry (2014-2020) in 2014, which requires that a smart logistics service system with a reasonable layout, advanced technology, convenience, efficiency, green environment protection, safety, and order be established by 2020. As the forefront of opening up to the southern region portal and the birthplace of the smart logistics industry, the Pearl River Delta economic zone includes 14 important cities in Guangdong Province. Seventy percent of the population and $85 \%$ of the GDP in Guangdong Province are located in this region. Especially as an important node area of the One Belt One Road Strategy and gathering area of the GuangdongHong Kong-Macao Greater Bay Area, the Pearl River Delta economic zone plays a very important role. The layout of the new urbanization and material demand at home and abroad makes the logistics service system in the Pearl River Delta economic zone face a severe situation. To solve this problem, in 2016, Guangdong Province designed the smart logistics industry development planning of Guangdong Province (2016-2020). Cities in the economic zone have also issued corresponding plans. Some efficient measures have been established to accelerate the development of the smart logistics industry, promote the healthy development of the smart logistics industry and the development of multimodal transport, strengthen provincial cross-regional logistics cooperation, and improve the regional logistics network. The goal is to establish an industrial management system that is compatible with the development of a smart and efficient logistics industry by 2020 .

As an important area in China's pan-Pearl River Delta region and a gateway to foreign trade, Guangdong Province has ranked first in the national economic aggregate for 30 consecutive years. However, there are obvious regional divisions. The nine inland cities of the Guangdong-Hong Kong-Macao Greater Bay Area (Guangzhou, Shenzhen, Foshan, Dongguan, Zhongshan, Zhuhai, Huizhou, Zhaoqing, and Jiangmen) account for nearly $80 \%$ of the total economic output of Guangdong Province. The 12 cities in the northern mountainous area (Qingyuan, Shaoguan, Heyuan, Meizhou, and Yunfu), eastern area (Chaozhou, Jieyang, Shantou, and Shanwei), and western area (Zhanjiang, Yangjiang, and Maoming) account for only approximately 20\%. The imbalance of regional economic development is partly due to convenient transportation, developed logistics and transportation, and frequent overseas trade in the Pearl River Delta economic zone. In addition, transportation in the northern mountainous area is inconvenient, resulting in difficulty transporting goods and contact with the outside world not being as frequent as in the Pearl River Delta economic zone.

With the promulgation of the Outline of the Development Plan for Guangdong-Hong Kong-Macao Greater Bay Area, the area will be built into a world-class bay area with an optimized industrial structure and smooth flow of production factors. In the future, the Pearl River Delta economic zone will have more frequent trade exchanges with Hong Kong, Macao, and overseas. Regions such as northern Guangdong should seize the opportunity to establish links with the Pearl River Delta economic zone. Then, what is the effect of the cross-regional cooperation of the logistics industry in the Pearl River Delta economic zone? Has the logistics industry significantly promoted the growth of the regional economy? Does the development of the logistics industry in local regions have a spillover effect on the economic development of surrounding regions? What are the remaining problems? These questions will be the focus of this article.

The remainder of this paper is organized as follows. Section 2 is the literature review. Section 3 includes the selection of the evaluation index and the model specification of the logistics development and gives the empirical results. In Section 4, the conclusion and discussion of this study are presented.

\section{Literature Review}

2.1. Relationship between Logistics Industry and Regional Economic Growth. The logistics industry and regional economy are interdependent and mutually promoting. The rapidly growing regional economic level can provide a good platform for the development of the logistics industry in the region and play a huge role in promoting the upstream and downstream industries of the logistics supply chain. In 
addition, the development of the logistics industry can continuously promote the steady growth of the regional economy and provide continuous energy in promoting the transformation of the regional economic growth mode, promoting the adjustment of the industrial structure, enhancing regional competitiveness, and accelerating regional economic integration construction [7]. Along with the process of economic globalization, exchanges between industries have accelerated. The division of labor has been improved. The cooperation between domestic and international logistics firms has been more obvious. All of these factors have promoted the rapid development of the logistics industry [8]. In recent years, the relationship between the logistics industry and regional economic growth has attracted the attention of many scholars. The research is divided into two aspects: bidirectional and unidirectional. Regarding the bidirectional influence, Li et al. [9] analyzed the correlation between logistics capacity and economic growth in 31 provinces and cities in China by using the typical correlation analysis method. They believed that there is a high correlation between logistics capacity and economic growth. Liu [10] established a dynamic coupling model between the logistics industry and the regional economy from the perspective of system dynamics, believing that it is difficult to achieve coordinated development in the short term but that there is a process of harmonious development in the medium and long term. In terms of unidirectional influence, Kim et al. [11] analyzed the relationship between the logistics industry and the economic growth of port cities in South Korea and believed that accelerating the development of the port logistics industry can significantly improve the employment rate and promote economic growth. Mohmand et al. [12] used unit root cointegration analysis and the Granger causality test to analyze the causal relationship between Pakistan's transportation infrastructure investment and long-term economic growth under the equilibrium model and believed that there was a two-way causal relationship in economically developed provinces, while there was a one-way causal relationship in less developed regions. Tsekeris [13] used panel data to measure the impact of domestic logistics development on the export trade in Greece and believed that the development of the logistics industry has a significant spatial spillover effect on the regional export trade. Kumar et al. [14] believed that logistics industries are mostly concentrated in metropolis circles. The agglomeration of transportation will have a significant impact on the regional economy.

From an empirical perspective, Cao and Rui [15] took Jiangsu Province in China as an example to study the spatial evolution mode of logistics industry agglomeration and discussed the degree of influence of factors such as the manufacturing industry and fixed investment on the logistics industry. Tang and Ding [16] empirically assessed the spatial spillover effect of logistics industry agglomeration and financial development on economic growth at the provincial level by using panel data in China. Cao and Deng [17] used panel data to measure the factors affecting the improved efficiency of the logistics industry in the Yangtze River Economic Belt and showed that industrial agglomeration, government intervention, and the degree of opening to the outside have significant influences on the improved efficiency of the logistics industry. Zhang and Zhao [18] used a logistic regression model to analyze the contribution of the Chinese logistics industry to the economy and showed that the logistics industry has entered a new stage of development since 2011.

\subsection{Comprehensive Development Index of the Logistics} Industry. The evaluation index of the logistics industry can comprehensively and objectively reflect the development status and potential problems of the logistics supply chain [19]. In terms of the selection of the evaluation indicators of the logistics industry, there is still a lack of scientific evidence for evaluation. Scholars mostly choose certain indicators to reflect the characteristics of the logistics industry. A systematic literature review found that researchers generally use two methods to quantify the development level of the logistics industry. The first method is to select a simple combination of some indicators to measure the logistics industry. For example, literatures $[8,20-22]$ select the turnover of goods to measure the level of logistics demand. Literatures $[23,24]$ select the network miles of the logistics industry (namely, total miles of roads, railways, and inland rivers) to measure the supply capacity of the logistics industry. Literatures $[17,25]$ selected the fixed asset investment of transportation, warehousing, and postal service to measure the level of logistics infrastructure. Literature [26] adopts three indicators, namely, the turnover of goods, the added value of the total output value of the logistics industry, and the patent invention authorization of the logistics industry, to measure logistics transportation, the development scale of the logistics industry, and the level of technological innovation of the logistics industry. Literature [27] measures the degree of development of the logistics industry by using three indicators: the total investment in fixed assets of the logistics industry, the adjustment of the industrial structure, and the total output value of the logistics industry. The second method is to use the entropy method to extract the characteristics of the logistics industry and obtain a new evaluation index. The idea was first proposed by Hwang and Yoon [28] in solving multiobjective decision planning. Then, it has been widely applied to the evaluation of comprehensive indicators. Due to the complexity of the logistics industry, its operations contain many departments and industries in the national economy. Therefore, a simple indicator cannot depict the comprehensive level of the logistics industry. Some researchers [29-34] use the entropy method for the integrated evaluation of logistics industry development, which can avoid bias due to subjective factors.

In the above literature, the theory and empirical aspects of logistics development and economic growth have become the focus. Especially with big data technology in rapid development, many cities have established logistics industrial parks. The logistics industry has a form of industrial agglomeration, which can promote the rapid development of the regional economy. In addition, we can see that most of the literature studies the relationship from the aspects of 
causality. Nevertheless, there is no research on the spatial effect of the logistics industry on economic growth based on the empirical evidence of specific regions and from the perspective of spatial measurement. Based on the panel data of 21 cities in Guangdong Province from 2007 to 2019, this paper analyzes the degree of spatial clustering of logistics industry development in Guangdong Province using spatial measurement and analyzes the spatial spillover effect of logistics industry development on economic growth by using the spatial Durbin model.

\section{Spatial Econometric Model}

In the last decade, there have been many studies on constructing a comprehensive evaluation index of logistics industry development. With the wide application of all types of new technologies in the logistics industry and the change and expansion of the meaning of "intelligence" itself, scholars have not yet unified the definition of the logistics industry. Thus, it is difficult to scientifically give the index of logistics industry development. Fortunately, there is a framework for constructing the index among the latest article [35]. Regarding the traditional evaluation index of logistics industry development, most scholars construct an evaluation index consisting of several level 1 indicators and level 2 indicators. Referring to this evaluation system, we will give a unique evaluation index of the logistic system.

\subsection{Construction of the Evaluation Indicator of the Logistics} Industry. This study mainly investigates the comprehensive development level of the logistics industry in Guangdong Province. This topic can be evaluated from multiple dimensions. Considering the availability, nonoverlapping, and comprehensiveness of the statistical data, this paper uses 11 level 2 indices of 4 level 1 indices, namely, the industrial scale, infrastructure, human resources, and industrial support, to construct the comprehensive evaluation index of the logistics industry development level. The detailed indices are shown in Table 1.

Next, we construct the comprehensive evaluation index of the logistics industry development level. As an objective evaluation method based on the mutation series method, the entropy method has been widely used in the evaluation system index of the industry development level [36]. This index allows for an effective evaluation of two-dimensional data (region and time). However, it cannot well describe the logistics industry development level after introducing the second-level indices. The overall entropy method proposed in literature [37] is adopted to construct the comprehensive evaluation index of the logistics industry development level. The specific steps are as follows.

(1) The judgment matrix $P$ is given by

$$
P=\left(x_{i j}^{t}\right)_{m T \times n}, 1 \leq i \leq m, 1 \leq j \leq n, 1 \leq t \leq T,
$$

where $m, n$, and $T$ represent the target regions, evaluation indices, and time spans, respectively.

(2) Normalize the judgment matrix $P$ :

$$
\begin{aligned}
& \left(x_{i j}^{t}\right)^{\prime}=\frac{x_{i j}^{t}-x_{j \min }}{x_{j \max }-x_{j \min }} \times 99+1, \quad \text { (positive indicator), } \\
& \left(x_{i j}^{t}\right)^{\prime}=\frac{x_{j \max }-x_{i j}^{t}}{x_{j \max }-x_{j \min }} \times 99+1, \quad \text { (negative indicator), }
\end{aligned}
$$

where $x_{j \max }$ and $x_{j \min }$ represent the maximum and minimum of the $j$ th index, respectively. As the second-level indices of the logistics industry development level are all positive indices, the first normalized method must be used to calculate the judgment matrix.

(3) Calculate the entropy and difference coefficient of $j$ th index:

$$
\begin{aligned}
& e_{j}=-\frac{1}{\ln \mathrm{mT}} \sum_{t=1}^{T} \sum_{i=1}^{m}\left[\frac{\left(x_{i j}^{t}\right)^{\prime}}{\sum_{t=1}^{T} \sum_{i=1}^{m}\left(x_{i j}^{t}\right)^{\prime}} \ln \left(\frac{\left(x_{i j}^{t}\right)^{\prime}}{\sum_{t=1}^{T} \sum_{i=1}^{m}\left(x_{i j}^{t}\right)^{\prime}}\right)\right], \\
& g_{j}=1-e_{j} .
\end{aligned}
$$

(4) Calculate the weight of $j$ th index:

$$
w_{j}=\frac{g_{j}}{\sum_{j=1}^{n} g_{j}} .
$$

(5) Calculate the comprehensive index of the logistics industry development level:

$$
F_{i}^{t}=\sum_{j=1}^{n} w_{j}\left(x_{i j}^{t}\right)^{\prime} .
$$

3.2. Variable Selection and Data Sources. The construction of the comprehensive index can reflect the relative importance of each level 2 index in the level 1 indices. Therefore, this method has been gradually adopted in the construction of economic index systems. The regional economic growth studied in this paper is the performance of the regional comprehensive strength and competitiveness. Referring to literature [38], per capita GDP is selected as the explained variable to measure the regional economic development index. Following literatures $[39,40]$, explanatory variables are divided into core explanatory variables and control variables. The core explanatory variable is the comprehensive index of the logistics industry development level (dl). In the selection of control variables, labor input (lab), government function (gov), capital investment (cap), the degree of opening to the outside (open), and urbanization (urb) are chosen. The detailed description of the indices is given in Table 2.

The data of pgdp, lab, gov, cap, open, and urb are from the 2008-2020 Statistical Yearbook of Guangdong Province. The data on $\mathrm{dl}$ are from 2008-2020 Statistical Yearbook of Chinese Cities. In order to eliminate the influence of currency, GDP data are adjusted based on 2007. 
TABLE 1: Evaluation indices of logistics industry development.

\begin{tabular}{|c|c|}
\hline First grade index & Second grade index \\
\hline Industrial scale & $\begin{array}{c}A_{11}: \text { post and telecommunications revenue (hundred million yuan) } \\
A_{12}: \text { revenue per square } \mathrm{km} \text { from post and telecommunications (million yuan } / \mathrm{km}^{2} \text { ) } \\
A_{13}: \text { total freight (ten thousand tons) } \\
A_{14}: \text { total freight per square } \mathrm{km}\left(\text { ton } / \mathrm{km}^{2}\right)\end{array}$ \\
\hline Infrastructure & $\begin{array}{c}A_{21}: \text { road density }\left(\mathrm{km} / \mathrm{km}^{2}\right) \\
A_{22}: \text { car ownership per capita }(\mathrm{car} / \mathrm{million} \text { persons }) \\
A_{23}: \text { mobile ownership per } \mathrm{km}^{2}\left(\text { ten thousand } / \mathrm{km}^{2}\right)\end{array}$ \\
\hline Human resources & $\begin{array}{l}A_{31}: \text { logistics employment (millions) } \\
A_{32}: \text { the proportion of logistics employment with respect to all industrial employees (\%) }\end{array}$ \\
\hline Industrial support & $\begin{array}{c}A_{41}: \text { number of industrial enterprises above the designated size (units) } \\
A_{42}: \text { number of wholesale and retail trade enterprises above the designated size (units) }\end{array}$ \\
\hline
\end{tabular}

TABLE 2: Variable description.

\begin{tabular}{|c|c|c|c|c|}
\hline Variable & Factor & Symbol & Definition & Unit \\
\hline Explained variable & Level of economic development & pgdp & Per capita GDP & Yuan \\
\hline \multirow{2}{*}{$\begin{array}{l}\text { Core explanatory } \\
\text { variable }\end{array}$} & $\begin{array}{l}\text { Comprehensive development level } \\
\text { of the logistics industry }\end{array}$ & $\mathrm{dl}$ & Overall entropy of the logistics industry & - \\
\hline & Labor input & lab & Total number of employees in three major industries & Million \\
\hline \multirow{4}{*}{ Control variable } & Government function & gov & $\begin{array}{l}\text { Proportion of investment in science, technology, and } \\
\text { education with respect to government public expenditures }\end{array}$ & $\%$ \\
\hline & Capital input & cap & Proportion of fixed investment with respect to GDP & $\%$ \\
\hline & Degree of opening to the outside & open & Proportion of imports and exports with respect to GDP & $\%$ \\
\hline & Urbanization & urb & $\begin{array}{l}\text { Proportion of urban population with respect to total } \\
\text { population }\end{array}$ & $\%$ \\
\hline
\end{tabular}

3.3. Model Specification. Regarding the impact of logistics development on regional economic growth, most studies are conducted within the framework of the Cobb-Douglas (CD) production function. The baseline empirical model is established as follows:

$$
\operatorname{pgdp}=F(\mathrm{dl}, \mathrm{lab}, \text { gov, cap, open, urb }) .
$$

In the simplified logarithmic linearization model, the parameter to be estimated (or regression coefficient) is the elasticity coefficient of the explained variable pgdp to its respective variable, as shown below:

$$
\begin{aligned}
\ln \text { pgdp }= & \beta_{0}+\beta_{1} \ln \mathrm{dl}+\beta_{2} \ln \mathrm{lab}+\beta_{3} \ln \text { gov } \\
& +\beta_{4} \ln \mathrm{cap}+\beta_{5} \ln \text { open }+\beta_{6} \ln \mathrm{urb}+\varepsilon,
\end{aligned}
$$

where $\varepsilon$ is the error term that obeys a normal distribution. Classic econometrics is based on the assumption of independent observations. However, in reality, the economic development and spatial factors among different regions are interrelated. Logistics infrastructure often has the characteristics of spatial connections. Classic OLS regression analysis ignores the spatial correlation and makes the estimated coefficients biased. Therefore, it is necessary to use spatial econometrics to test the spatial effect of the comprehensive development level of the logistics industry. If there is a spatial effect, spatial econometric analysis must be used.

Before adopting the spatial econometric model, the spatial autocorrelation of data needs to be tested. The spatial autocorrelation test is a mathematical method to calculate the correlation of the same variable among different geographical locations [41]. The global Moran's index is commonly used. Its formula is as follows:

$$
I=\frac{\sum_{i=1}^{n} \sum_{j=1}^{n} w_{i j}\left(x_{i}-\bar{x}\right)\left(x_{j}-\bar{x}\right)}{s^{2} \sum_{i=1}^{n} \sum_{j=1}^{n} w_{i j}}
$$

where $n$ is the total number of regional units; $w_{i j}$ is the element value of the spatial weight matrix; $x_{i}$ is the observed value of region $i$; and $\bar{x}$ and $s^{2}$ are the mean and variance, respectively. The range of the global Moran's index is $[-1,1]$. If the global Moran's index is negative, it means that there is a negative spatial correlation. If the global Moran's index is positive, it means that there is a positive spatial correlation. If the global Moran's index is zero, it means that there is no correlation; that is, there is a random distribution. In the setting of the spatial weight matrix, the 0-1 matrix, geographic adjacency matrix, economic adjacency matrix, and inverse geographic adjacency matrix are commonly used. Since this paper mainly studies the spatial effect of logistics on economic growth and quantifies the spatial spillover effect of economic development in the region and its nearby areas, the economic adjacency matrix is selected as the spatial weight matrix. Generally, the closer the economic development levels are, the greater the weight that will be given. This is conducive to the flow of resources and goods, which has a positive effect on the logistics industry. On the basis of literatures $[42,43]$, the economic adjacency matrix is constructed and standardized. 


$$
W= \begin{cases}\frac{1 /\left|e_{i}-e_{j}\right|}{\sum_{j=1}^{n} 1 /\left|e_{i}-e_{j}\right|}, & (i \neq j), \\ 0, & (i=j),\end{cases}
$$

where $e_{j}$ is the GDP of region $j$. Using the economic adjacency matrix, Table 3 lists the global Moran's index of the comprehensive development level of the logistics industry from 2007 to 2019. In addition, Figure 1 shows the trend of the global Moran's index.

Table 3 and Figure 1 show that, from 2007 to 2019, the global Moran's index of the comprehensive development level of logistics industry was greater than 0 , and all passed the significance test at the $1 \%$ level, indicating that the comprehensive development level of the logistics industry in Guangdong Province shows spatial agglomeration. The global Moran's index had no obvious change in the first 6 years. This might be caused by the change in the economic development mode. Rapid economic growth promoted the optimization and adjustment of the industrial structure. Fierce competition was inevitable. However, there was a significant increase in the last 7 years since 2012. This might be because China began to plan the "Guangdong-Hong Kong-Macao Greater Bay Area.” Nine cities in Guangdong Province began to form a joint force for industrial layout and complementary advantages, which accelerated the spatial clustering characteristics of regional development. Coupled with the rapid development of new technologies and the impact of the "Medium-Long-Term Plan for Development of Logistics Industry (2014-2020)" issued by Guangdong Province, it is urgent to transform the development mode and upgrade the transportation of the logistics industry. Our results are consistent with Zhang and Zhao [18] at the national level. It is concluded that the comprehensive development level of the logistics industry in 21 cities of Guangdong Province is not a random distribution but has the characteristics of significant spatial agglomeration.

In order to analyze spatial differences between different regions, a local spatial autocorrelation model is introduced. Moran's scatter plot is used. Moran's scatter plot divides two-dimensional space into four quadrants, which are highhigh, low-high, low-low, and high-low spatial correlations, respectively. The local spatial autocorrelation value $I_{i}$ is calculated as follows:

$$
I_{i}=\frac{\left(x_{i}-\bar{x}\right)}{s^{2}} \sum_{j=1}^{n} w_{i j}\left(x_{j}-\bar{x}\right) .
$$

If $I_{i}>0$ (in the first and third quadrants), it indicates that the target region and its nearby areas show a high-high or low-low spatial clustering feature, namely, positive correlation. If $I_{i}<0$ (in the second and fourth quadrants), it indicates that the target region and its nearby areas show a high-low or low-high spatial clustering feature, namely, negative correlation. If $I_{i}=0$, it indicates that the target region has no spatial clustering characteristic with surrounding areas.
Figure 2 shows Moran's scatter plot of the comprehensive development level of the logistics industry in 2007, 2011, 2015, and 2019. The results show that most of the 21 cities are located in the first quadrant and third quadrant and have obvious characteristics of high-high and low-low agglomeration. Therefore, the radiation effect of the logistics industry in each city on its surrounding cities is gradually increasing.

\subsection{Empirical Result}

3.4.1. Estimation of Nonspatial Panel Data. In order to operate an appropriate econometric model, this paper first estimates the nonspatial econometric model. The results are shown in Table 4. The table shows that the Durbin-Watson value is 1.843 , which is close to 2 , indicating that there is no first-order autocorrelation of the residual sequence. It is less affected by heteroscedasticity. The $F$ test satisfies that $p \leq 0.001$, indicating that the fixed-effects model is better than the mixed OLS model. The LM test satisfied $p \leq 0.001$, indicating that the random-effects model was significant and better than the mixed OLS model. The Hausman test suggests that the null hypothesis that fixed effects and random effects are indistinguishable is rejected at the $1 \%$ level. Thus, the fixed-effects model is better than the random-effects model.

The above analysis shows that Moran's index of the comprehensive development level of the logistics industry is significant. Besides, the mixed OLS regression cannot be used in the model of the influence of the logistics industry on regional economic development, which means that the explained variable and explanatory variables have spatial correlation. The spatial relationship should be incorporated into the regression model. Therefore, it is necessary to introduce a spatial econometric model.

3.4.2. Estimation of Spatial Panel Data. There are three types of spatial econometric models: the spatial autoregressive model (SAR), the spatial error model (SEM), and the spatial Durbin model (SDM). The SAR, also known as the spatial lag model (SLM), mainly investigates the spatial correlation of the dependent variable in different regions and calculates whether the variable has spillover effects. The SEM mainly studies the spatial correlation existing in the error perturbation term. The SDM is a general form of the SAR and SEM that mainly considers the combined effects of spatial lag explanatory variables and explained variable on explained variable [44]. In practice, it is generally necessary to determine whether the SDM can be degraded into the SAR or SEM. This needs to be tested by the Wald test, LR test, and LM test [45].

Now, we check whether the SDM can be degraded into the SAR or SEM. In this section, the Wald test and LR test are used. The null hypotheses of the tests are $H_{0}^{1}: \theta=0, H_{0}^{2}: \theta+\rho \beta=0$, respectively. The results are shown in Table 5.

From Table 5, the $p$ values of the Wald spatial lag and LR spatial error are both less than 0.05 , indicating that the SDM 
TABLE 3: Global Moran's index.

\begin{tabular}{lccccccccccccc}
\hline Year & 2007 & 2008 & 2009 & 2010 & 2011 & 2012 & 2013 & 2014 & 2015 & 2016 & 2017 & 2018 & 2019 \\
\hline Moran's index & 0.378 & 0.392 & 0.408 & 0.401 & 0.399 & 0.396 & 0.400 & 0.407 & 0.415 & 0.421 & 0.426 & 0.433 & 0.437 \\
Statistic & 2.778 & 2.874 & 2.973 & 2.929 & 2.925 & 2.907 & 2.939 & 2.984 & 3.039 & 3.082 & 3.113 & 3.155 & 3.185 \\
$p$ value & 0.005 & 0.004 & 0.003 & 0.003 & 0.003 & 0.004 & 0.003 & 0.003 & 0.002 & 0.002 & 0.002 & 0.002 & 0.001 \\
\hline
\end{tabular}
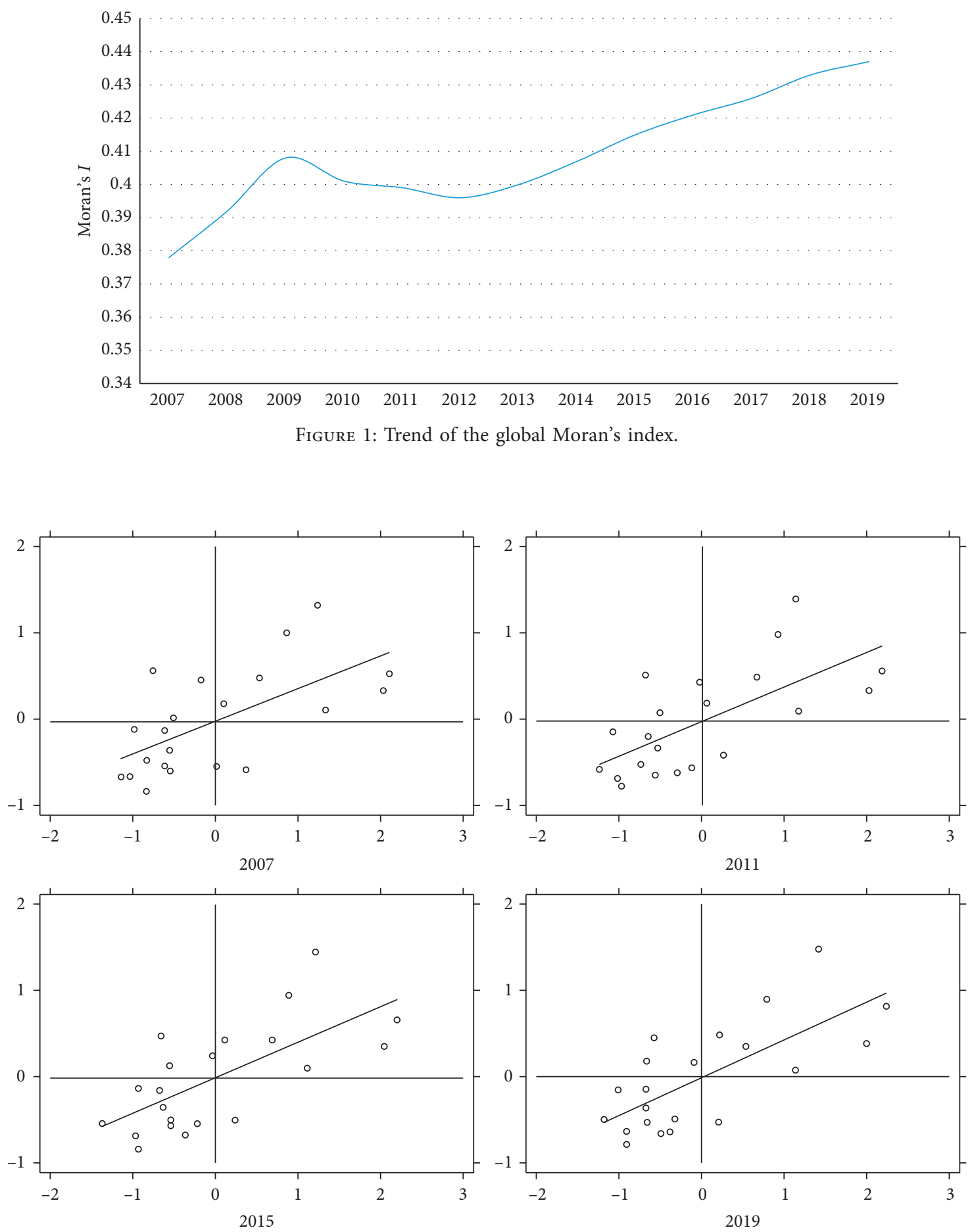

Figure 2: Local Moran's scatter plot. 
TABLE 4: Estimation results of nonspatial panel data.

\begin{tabular}{lccc}
\hline Variable & Mixed OLS & Random effects & Fixed effects \\
\hline lndl & $1.009^{* * *}[19.39]$ & $0.9464^{* * *}[23.56]$ & $0.9523^{* * *}[20.61]$ \\
lnlab & $-0.4227^{* * *}[-7.77]$ & $-0.2094^{* * *}[-2.83]$ & $-0.0770[-0.82]$ \\
lngov & $0.014[0.14]$ & $0.1936^{* * *}[2.89]$ & $0.1587^{* *}[2.29]$ \\
lncap & $0.116^{* *}[2.58]$ & $0.1547^{* * *}[4.72]$ & $0.1448^{* * *}[4.33]$ \\
lnopen & $-0.026[-1.03]$ & $-0.1623^{* * *}[-5.08]$ & $-0.1621^{* * *}[-3.65]$ \\
lnurb & $-0.124[-0.93]$ & $0.2658^{* * *}[2.59]$ & $0.2535^{* *}[2.40]$ \\
R_squared & 0.8716 & 0.8885 & 0.8896 \\
D.W. & 1.843 & $47.58(0.000)^{* * *}$ & $811.13(0.000)^{* * *}$ \\
F test & & $12.37(0.000)^{* * *}$ & \\
LM test & & & \\
Hausman test & &
\end{tabular}

Note: the $t$ values and $p$ values are shown in brackets [ ] and ( ), respectively. ${ }^{*},{ }^{* *}$, and ${ }^{* * *}$ indicate statistical significance at the $10 \%, 5 \%$, and $1 \%$ levels, respectively. These notes are similar in all other tables hereinafter.

TABLE 5: Wald test and LR test.

\begin{tabular}{lcc}
\hline Test & Statistic & $p$ value \\
\hline Wald spatial lag & 39.15 & $\leq 0.001$ \\
Wald spatial error & 14.65 & $\leq 0.01$ \\
LR spatial lag & 44.76 & $\leq 0.001$ \\
LR spatial error & 44.55 & $\leq 0.001$ \\
Hausman test & 32.56 & $\leq 0.001$ \\
\hline
\end{tabular}

should be used. According to the Hausman test, the chisquared statistic was 32.56 and $p \leq 0.001$ at a significance level of $1 \%$. It shows that fixed effects are better than random effects. Therefore, the SDM with fixed effects is as follows:

$$
\begin{aligned}
\ln \operatorname{pgdp}_{i, t}= & \rho \sum_{j=1}^{n} w_{i j} \ln \operatorname{pgdp}_{i, t}+\beta_{0}+\beta_{1} \ln \mathrm{dl}_{i, t}+\beta_{2} \ln \operatorname{lab}_{i, t}+\beta_{3} \ln \operatorname{gov}_{i, t}+\beta_{4} \ln \operatorname{cap}_{i, t}+\beta_{5} \ln \text { open }_{i, t} \\
& +\beta_{6} \ln \operatorname{urb}_{i, t}+\theta_{1} \sum_{j=1}^{n} w_{i j} \ln \mathrm{dl}_{i, t} \\
& +\theta_{2} \sum_{j=1}^{n} w_{i j} \ln \operatorname{lab}_{i, t}+\theta_{3} \sum_{j=1}^{n} w_{i j} \ln \operatorname{gov}_{i, t}+\theta_{4} \sum_{j=1}^{n} w_{i j} \ln \operatorname{cap}_{i, t}+\theta_{5} \sum_{j=1}^{n} w_{i j} \ln \operatorname{open}_{i, t}+\theta_{6} \sum_{j=1}^{n} w_{i j} \ln \operatorname{urb}_{i, t}+\varepsilon_{i, t} .
\end{aligned}
$$

$\rho, \beta$, and $\theta$ are the parameters to be estimated. $\rho$ is the spatial autoregressive coefficient. Its value represents the interaction effect between the economic growth levels of target regions. If $\rho>0$ (or $\rho<0$ ), it means a positive (or negative) interaction. $\beta$ is the elasticity coefficient of the effects of the explanatory variables on explained variable. $\theta$ represents the elasticity coefficient of the effects of the explanatory variables on explained variable in the surrounding area. It is known that the fixed-effects model can be divided into spatial fixed effects, time fixed effects, and space-time fixed effects. In order to select a better model, we tested the three models individually and reported the results in Table 6 .

Table 6 shows that the significance of the coefficients with time fixed effects is the best. Furthermore, the $R^{2}$, loglikelihood, and rho of the time fixed-effects model are acceptable. Therefore, a time fixed-effects model was selected for analysis. Table 6 shows that the regression coefficient of the comprehensive development level of the logistics industry is 0.2590 , which passed the significance test at the $1 \%$ level. This indicates that the development of the logistics industry has a significant positive effect on promoting regional economic growth. For every 1\% increase in the comprehensive development index of the logistics industry, economic development will increase by $0.2590 \%$. Regarding the control variables, the regression coefficients of lab, gov, cap, open, and urb are 0.1056, 0.0740, 0.1033, 0.0973, and 0.0052 , respectively, which all passed the significance test at the $5 \%$ level. This indicates that, for a $1 \%$ increase in each index, economic development will increase by $0.1056 \%$, $0.0740 \%, 0.1033 \%, 0.0973 \%$, and $0.0052 \%$, respectively. This conclusion is consistent with Liu et al. [46].

3.4.3. Spillover Effects. Analysis of the point estimation of the SDM may result in incorrect conclusions [47]. In order 
TABLE 6: Estimation result of the SDM.

\begin{tabular}{|c|c|c|c|}
\hline Variable & Spatial fixed effects & Time fixed effects & Space-time fixed effects \\
\hline lndl & $0.3469(7.82)^{* * *}$ & $0.2590(16.24)^{* * *}$ & $0.2645(5.98)^{* * *}$ \\
\hline $\operatorname{lnlab}$ & $-0.1431(-3.23)^{* * *}$ & $0.1056(-7.31)^{* * *}$ & $0.1155(-2.72)^{* * *}$ \\
\hline lngov & $0.0308(1.05)$ & $0.0740(-1.92)^{*}$ & $0.0473(-1.49)$ \\
\hline Lncap & $0.0215(1.27)$ & $0.1033(-2.63)^{* * *}$ & $0.0275(1.77)^{*}$ \\
\hline lnopen & $0.0827(-3.97)^{* * *}$ & $0.0973(3.67)^{* * *}$ & $0.0444(-2.19)^{* *}$ \\
\hline lnurb & $0.0023(0.05)$ & $0.0052(-1.96)^{*}$ & $-0.0790(-1.91)^{*}$ \\
\hline $\mathrm{W}^{*} \operatorname{lndl}$ & $-0.1610(-3.08)^{* * *}$ & $0.0089(3.44)^{* * *}$ & $-0.0958(-2.46)^{* *}$ \\
\hline $\mathrm{W}^{*} \operatorname{lnlab}$ & $0.0652(0.88)$ & $-0.0585(-3.86)^{* * *}$ & $0.0697(0.91)$ \\
\hline $\mathrm{W}^{*}$ lngov & $0.0198(0.42)$ & $0.0557(0.36)$ & $-0.1983(-3.17)^{* * *}$ \\
\hline $\mathrm{W}^{*} \operatorname{lncap}$ & $0.0259(1.03)$ & $-0.1499(2.05)^{* * *}$ & $0.0200(0.79)$ \\
\hline $\mathrm{W}^{*}$ lnopen & $0.1006(3.29)^{* * *}$ & $0.1712(4.00)^{* * *}$ & $0.1713(4.87)^{* * *}$ \\
\hline $\mathrm{W}^{*} \operatorname{lnurb}$ & $0.2447(2.92)^{* * *}$ & $-0.4910(-7.53)^{* * *}$ & $-0.0567(-0.69)$ \\
\hline rho & $0.8061(29.31)^{* * *}$ & $0.2554(-7.53)^{* * *}$ & $0.1569(1.96)^{*}$ \\
\hline R_squared & 0.9308 & 0.9481 & 0.6902 \\
\hline Log-L & 396.7439 & 394.0594 & 462.4181 \\
\hline
\end{tabular}

to specifically reflect the impact of the logistics industry on economic growth, the SDM is decomposed into direct effects, indirect effects (or spillover effects), and total effects by using a partial differential equation. The results are shown in Table 7.

As Table 7 shows, the direct effect coefficient of $\mathrm{dl}$ is 0.4074, which passes the significance test at the $1 \%$ level, showing that increasing the proportion of the logistics industry can significantly promote economic growth in the local region. The main reason is that the logistics industry has strengthened the effective communication among various industries through the optimal allocation of resources within the region. Furthermore, the logistics industry reduced environmental pollution and stimulated market demand, which promoted regional economic growth. The indirect effect coefficient of $\mathrm{dl}$ is 0.3596 , which passes the significance test at the $1 \%$ level. This indicates that the increase in the integrated development of the logistics industry in adjacent regions has a positive impact on the economic growth in the region, that is, creating a positive spatial spillover effect. The comprehensive development of the logistics industry should not only promote the construction of logistics infrastructure in the region but also place the region in a more open and inclusive external environment so as to better play the role of the logistics industry in promoting economic growth. As for the control variables, the direct effect coefficients of lab, cap, open, and urb are $-0.3422,-0.0938,0.1134$, and -0.3259 , respectively; and the indirect coefficients are $-0.5545,0.1620,0.2503$, and -0.9537 , respectively, which all pass the significance test at the $10 \%$ level. However, gov failed the significance test at the $10 \%$ level.

3.5. Robustness Test. In order to test the robustness of the SDM, the space weight matrix is converted into a $0-1$ adjacency matrix and inverse adjacency matrix. The SDM with time fixed effects is used again. The above steps were repeated, and the results are reported in Table 8 . The results show that when the spatial weight matrix is changed, the comprehensive development level of the logistics industry
Table 7: Spatial effect decomposition in the time-fixed-effects model.

\begin{tabular}{lccc}
\hline Variable & Direct effects & Indirect effects & Total effects \\
\hline lndl & $0.4074(17.68)^{* * *}$ & $0.3596(8.37)^{* * *}$ & $0.7670(15.53)^{* * *}$ \\
lnlab & -0.3422 & -0.5545 & -0.8967 \\
lngov & $(-8.18)^{* * *}$ & $(-5.41)^{* * *}$ & $(-8.14)^{* * *}$ \\
lncap & $-0.0619(-0.76)$ & $0.0586(0.29)$ & $-0.0033(-0.01)$ \\
lnopen & $0.1134(4.29)^{* * *}$ & $0.2503(3.93)^{* * *}$ & $0.3637(4.79)^{* * *}$ \\
lnurb & -0.3259 & -0.9537 & -1.2796 \\
& $(-3.17)^{* * *}$ & $(-6.93)^{* * *}$ & $(-6.77)^{* * *}$ \\
\hline
\end{tabular}

TABLE 8: Robustness test of the SDM.

\begin{tabular}{lcc}
\hline \multirow{2}{*}{ Variable } & \multicolumn{2}{c}{ Type of spatial weight matrix } \\
& $0-1$ adjacency matrix & Inverse adjacency matrix \\
\hline lndl & $0.2707(13.02)^{* * *}$ & $0.2606(21.24)^{* * *}$ \\
lnlab & $0.1155(-6.26)^{* * *}$ & $0.1828(-12.70)^{* * *}$ \\
lngov & $0.1024(-1.15)$ & $0.0722(-0.99)$ \\
lncap & $0.0878(-1.78)^{*}$ & $0.1858(-4.85)^{* * *}$ \\
lnopen & $0.0975(3.88)^{* * *}$ & $0.0284(1.47)$ \\
lnurb & $-0.0710(-2.37)^{* * *}$ & $0.0293(0.32)$ \\
$\mathrm{W}^{*}$ lndl & $-0.1221(-3.28)^{* * *}$ & $0.0406(10.19)^{* * *}$ \\
$\mathrm{~W}^{*}$ lnlab & $0.0980(2.47)^{* * *}$ & $-0.0199(-9.31)^{* * *}$ \\
$\mathrm{~W}^{*}$ lngov & $-0.0384(-2.84)^{* * *}$ & $0.0474(4.43)^{* * *}$ \\
$\mathrm{~W}^{*}$ lncap & $-0.3740(-3.52)^{* * *}$ & $-0.3934(-3.25)^{* * *}$ \\
$\mathrm{~W}^{*}$ lnopen & $0.3340(5.95)^{* * *}$ & $-0.4270(-3.55)^{* * *}$ \\
$\mathrm{~W}^{*}$ lnurb & $0.0803(0.30)$ & $-0.5988(-2.14)^{* *}$ \\
rho & $0.7615^{* * *}$ & $0.3676^{* * * *}$ \\
$R^{2}$ & 0.9234 & 0.8892 \\
Log-L & 369.8490 & 119.6157 \\
\hline
\end{tabular}

also shows a significant positive spatial effect. The symbols in the control variables remain unchanged except for urb. The finding has not changed, showing that the results in this study are robust.

\section{Conclusion and Suggestions}

Based on the panel data of 21 cities in Guangdong Province from 2007 to 2019, this paper empirically analyzes the spatial 
influence and spillover effect of the comprehensive development level of the logistics industry on regional economic growth from the perspective of spatial econometrics. The results show that the comprehensive development level of the logistics industry presents typical spatial agglomeration characteristics. The logistics industry can not only promote the economic development of the region but also have certain spatial spillover effects on the surrounding areas, which is the strategic pattern of accelerating the optimization of the layout of the logistics industry and coordinated development. Compared with previous research, the main contribution of this paper is that it constructs a quantitative index of the comprehensive development level of the logistics industry by using the overall entropy weight method. By using the spatial Durbin model, the comprehensive development level of the logistics industry shows a significant positive effect on the regional economy. The elasticity coefficient is 0.2590 and has statistical significance at the $1 \%$ level, which shows that the development of the logistics industry can indeed be a significant factor in economic growth. Furthermore, the spatial spillover is 0.3596 , which is significant at the $1 \%$ level, indicating that the development of the logistics industry in the region can promote the economic growth of the surrounding regions.

The development of the logistics industry plays a very important role in promoting economic growth. It connects production and consumption, domestic and foreign, and urban and rural areas. The logistics industry has a positive impact on regional economic development and the promotion of its comprehensive strength. Overall, the comprehensive development level of the logistics industry in Guangdong Province is high and has a spatial agglomeration effect. The linkage effect between the development level of the logistics industry and the regional economy is obvious. However, some regions, especially the mountainous areas of northern and eastern China, have a certain lag effect compared with the local economic development level. The logistics infrastructures are relatively poor, and the degree of integration with other regions is not high enough. There is still a certain gap from the goal of a reasonable layout of, orderly competition in, and efficient service in the logistics industry. Based on the above analysis, we propose the following suggestions.

First, infrastructure construction should be increased and regional logistics equipment should be upgraded. These items are helpful to promoting regional economic transformation and development, which are crucial to the construction of efficient and smart logistics network systems. Guangdong Province, especially the Pearl River Delta economic zone, has an advantageous geographical location and a good development foundation. However, some logistics facilities are outdated, especially in the northern and eastern regions, which seriously restricts the development of the regional economy. Therefore, it is urgent to upgrade and transform the logistics networks in the northern and eastern regions. The traffic layout and industry optimization need to be constantly improved so as to ensure the smooth flow of the logistics industry in mountainous areas. For the western area, policy support should be increased and the connection between the western areas and the Guangdong-Hong Kong-Macao Greater Bay Area should be accelerated. Furthermore, these areas should also take the initiative to connect with the industries of the Beibu Gulf and Hainan Free Trade Zone so as to make use of regional advantages and develop agricultural modernization.

Second, the development of science and technology, especially the development of fintech to reduce the turnover costs of the logistics industry, should be accelerated to improve the efficiency of the flow of goods and the logistics service level. As a part of smart enterprises, controlling the costs of logistics enterprises is the core of management requirements. The improvement of urbanization can effectively reduce the frequency of the turnover of goods, save the transportation time of goods, and reduce the transit costs, which are of great significance for new rural construction and further optimal allocation of resources integration. The urbanization of 9 cities in the Guangdong-Hong Kong-Macao Greater Bay Area is at the forefront of the entire province. The transformation of urbanization is conducive to the upgrading of industries including the logistics industry and the integration of urban and rural areas. However, the urbanization levels of Yunfu and Shaoguan are low, so more attention should be given to industrial development in the future.

Third, we focus on building superior logistics industrial parks, promoting the process of logistics "integration," and implementing the "one-stop" service mode. Most logistics enterprises in Guangdong Province are small in scale and relatively dispersed, which reduces the service capacity and efficiency. Therefore, it is necessary to integrate the resources of small-scale logistics enterprises so as to form large-scale enterprises with lower costs and more convenience. In this regard, Shenzhen city has played an exemplary role. As early as the beginning of this century, Shenzhen city proposed establishing a logistics industrial park. It made full use of the geographical advantages of land, sea, and air; strengthened the material circulation between Shenzhen, Hong Kong, and overseas; and promoted employment while driving the rapid development of a number of industries.

Finally, coordination and cooperation among governments should be strengthened, resources and information sharing should be implemented, and the multiangle and integrated development of the smart logistics industry should be realized. There is a low level of logistics informatization and a lack of advanced logistics equipment, as well as inadequate standardization of logistics technology and the single service function of logistics talent, in the mountainous areas. This requires increasing input in informatization and providing support to logistics enterprises in terms of policies and funds. In addition, enterprises should be encouraged to recommend smart technology, establish information exchange, and share platforms among logistics enterprises. Furthermore, the regions should strengthen their cooperation to effectively avoid resource waste through a win-win cooperation mode and encourage the enterprises to make full use of big data and artificial intelligence to conduct misplaced development. 


\section{Data Availability}

The data used to support the findings of this study are available from the corresponding author upon request.

\section{Conflicts of Interest}

The authors declare that they have no conflicts of interest.

\section{Acknowledgments}

This work was supported by the Foundation of Hubei Key Laboratory of Applied Mathematics (no. AM201807), Scientific Foundation of Hubei University of Economics (nos. XJ19BS09 and 790314), Research Project of College of Engineering and Technology, Yangtze University (no. 2020KY07), and Scientific Research Projects of Hubei Provincial Department of Education (no. B2020341).

\section{References}

[1] Y. Li, J. Zhou, J. Tian, X. Zheng, and Y. Y. Tang, "Weighted error entropy-based information theoretic learning for robust subspace representation," IEEE Transactions on Neural Networks and Learning Systems, vol. 32, pp. 1-16, 2021.

[2] Y. Li, R. Liang, W. Wei, W. Wang, J. Zhou, and X. Li, "Temporal pyramid network with spatial-temporal attention for pedestrian trajectory prediction," IEEE Transactions on Network Science and Engineering, vol. 8, pp. 1-2, 2021.

[3] Y. Li, J. Zhou, X. Zheng, J. Tian, and Y. Y. Tang, "Robust subspace clustering with independent and piecewise identically distributed noise modeling," in Proceedings of the IEEE Conference on Computer Vision and Pattern Recognition, vol. 2019, pp. 8712-8721, Long Beach, CA, USA, June 2019.

[4] G. Ji, "Ecological Supply Chains Design Mechanism Based on Virtual Enterprises," in Proceedings of the 2008 IEEE International Conference on Service Operations and Logistics, and Informatics, IEEE, Beijing, China, October 2008.

[5] L. Chen and F. Xu, "Study on the collaborative innovation oriented SDN enterprise ecological collaboration model," International Business Research, vol. 4, no. 2, p. 112, 2011.

[6] X. Xu and Y. Wang, "Study on spatial spillover effects of logistics industry development for economic growth in the Yangtze River Delta city cluster based on spatial Durbin model," International Journal of Environmental Research and Public Health, vol. 14, Article ID 1508, 2017.

[7] L. Guo and H. Guo, "Research on Granger causality between logistics industry and regional economic development in Yangtze River Delta," China Market, vol. 11, pp. 1-4, 2020.

[8] T. Feng and Y. Liang, "The research of FDI threshold effect on the logistics industry to economic growth," Statistics and Information Forum, vol. 30, no. 8, pp. 49-55, 2015.

[9] Q. Li, F. Jin, and P. Sun, "Analysis of canonical correlation between regional logistics capability and regional economic development-based on national panel data," Soft Sciences, vol. 24, pp. 75-79, 2010.

[10] W. Liu, "Dynamic coupling mechanism and empirical study on regional logistics system and economy growth," Economic Geography, vol. 31, pp. 1493-1498, 2011.

[11] S.-Y. Kim, H. Park, H.-M. Koo, and D.-K. Ryoo, "The effects of the port logistics industry on port city's economy," Journal of Navigation and Port Research, vol. 39, no. 3, pp. 267-275, 2015.
[12] Y. T. Mohmand, A. Wang, and A. Saeed, "The impact of transportation infrastructure on economic growth: empirical evidence from Pakistan," Transportation Letters, vol. 9, no. 2, pp. 63-69, 2016.

[13] T. Tsekeris, "Domestic transport effects on regional export trade in Greece," Research in Transportation Economics, vol. 61, pp. 2-14, 2016.

[14] I. Kumar, A. Zhalnin, A. Kim, and L. J. Beaulieu, "Transportation and logistics cluster competitive advantages in the U.S. regions: a cross-sectional and spatio-temporal analysis," Research in Transportation Economics, vol. 61, pp. 25-36, 2017.

[15] B. Cao and J. Rui, "Influence of manufacturing agglomeration on spatial evolution of logistics industry: taking Jiangsu province as an example," Areal Research and Development, vol. 38, no. 4, pp. 44-49, 2019.

[16] Y. Tang and J. Ding, "Spatial spillover effects of logistics industry agglomeration and financial development on economic growth: an analysis of spatial Durbin model based on provincial data in China," Xinjiang State Farms Economy, vol. 11, pp. 63-72, 2018.

[17] B. Cao and L. Deng, "Influencing factors of logistics industry growth efficiency in Yangtze River Economic Belt," Economic Geography, vol. 39, no. 7, pp. 148-157, 2019.

[18] Y. Zhang and J. Zhao, "Empirical study on the contribution of logistics industry development to economic growth in China," China Storage \& Transport, vol. 8, pp. 124-126, 2019.

[19] W. Liu, S. Wang, D. Dong, and J. Wang, "Evaluation of the smart logistics ecological index: evidence from China," Journal of Cleaner Production, vol. 274, Article ID 123127, 2020.

[20] X. Gao and F. Meng, "Spatial econometric analysis of logistics industry and economic growth in Guangdong province," Journal of Chongqing University of Technology (Social Science), vol. 28, no. 3, pp. 58-63, 2014.

[21] G. Yu, "An empirical study on the relationship between logistics and regional economic development in Zhuhai," Logistics Engineering and Management, vol. 41, no. 6, pp. 10-12, 2019.

[22] J. Cao and Z. Hu, "Quantitative analysis of smartlogistics industry and economic growth in Hubei province," Journal of Commercial Economics, vol. 2020, no. 2, pp. 107-109, 2020.

[23] J. Wang and R. Sun, "The influence of regional logistics on regional economic development in Beijing-Tianjin-Hebei metropolitan area," Journal of Commercial Economics, vol. 24, pp. 84-87, 2019.

[24] S. Hou and Y. Hu, "The influence of smart logistics factor input on agricultural economy in Guizhou from 1995 to 2018," Guizhou Social Sciences, vol. 3, pp. 126-132, 2019.

[25] Y. Tian and M. Yang, "A study on the relationship between logistics development and regional economic growth in Shanxi," Railway Transport and Economy, vol. 41, no. 1, pp. 13-17, 2019.

[26] T. Wu and J. Wang, "Logistics growth, economic growth and technological innovation based on VAR model," Journal of Industrial Technological Economics, vol. 3, pp. 116-122, 2019.

[27] X. Tang and Z. Li, "Research on economic growth and logistics industry development in Yangtze River Delta region-State space model based on panel data," Logistics Engineering and Management, vol. 37, no. 5, pp. 12-14, 2015.

[28] C. Hwang and K. Yoon, Multiple Attribute Decision Making: Method and Application, Springer-Verlag, New York, NY, USA, 1981. 
[29] S. Xie and H. Cai, "The spatial-temporal evolution and its influence factors of logistics development in Yangtze River Delta," World Regional Studies, vol. 24, no. 3, pp. 118-125, 2015.

[30] H. Cai and Y. Xu, "Research on the development pattern and effect mechanism of logistics industry in the Yangtze River Delta-based on the perspective of spatial economics," East China Economic Management, vol. 30, no. 1, pp. 15-23, 2016.

[31] R. Liu, "Research on spatial pattern evolution and spillover effect of "the new silk road economic belt" logistics competitiveness based on ESDA," Statistics \& Information Forum, vol. 32, no. 6, pp. 106-112, 2017.

[32] $\mathrm{Z}$. $\mathrm{Wu}, \mathrm{J}$. Xu, and $\mathrm{Z}$. Xu, "A multiple attribute group decision making framework for the evaluation of lean practices at logistics distribution centers," Annals of Operations Research, vol. 247, no. 2, pp. 735-757, 2016.

[33] Z. Zhang and J. David, "An entropy-based approach for assessing the operation of production logistics," Expert Systems with Applications, vol. 119, pp. 118-127, 2019.

[34] Y. Xiong, J. Zhao, and J. Lan, "Performance evaluation of food cold chain logistics enterprise based on the AHP and entropy," International Journal of Information Systems and Supply Chain Management, vol. 12, no. 2, pp. 57-67, 2019.

[35] W. Liu, S. Wang, Y. Lin, D. Xie, and J. Zhang, "Effect of intelligent logistics policy on shareholder value: evidence from Chinese logistics companies," Transportation Research Part E, vol. 137, Article ID 101928, 2020.

[36] J. Tang and X. Zhang, Spatio-temporal Evolution, Driving Forces and Spillover Effects of Logistics Industry Development: On Spatial Panel Data Analysis of Chinese Provincial Panel Data, pp. 11-21, Finance and Trade Research, 2015.

[37] X. Pan, Q. Liu, and X. Peng, "Evalution and analysis of regional innovation ability in China based on overall entropy method," Operations Research and Management Science, vol. 24, pp. 155-162, 2015.

[38] G. Qi, W. Shi, K.-C. Lin, K. F. Yuen, and Y. Xiao, "Spatial spillover effects of logistics infrastructure on regional development: evidence from China," Transportation Research Part A: Policy and Practice, vol. 135, pp. 96-114, 2020.

[39] H. Yang, J. Zheng, and Z. Cheng, "Spatial econometric analysis of influencing factors of logistics industry along "the Belt and Road"' Journal of Industrial Technological Economics, vol. 5, pp. 112-120, 2019.

[40] R. Wang, X. Zhe, and F. Chen, "Spatial spillover effect of logistics industry on population and land urbanization," Urban Problems, vol. 12, pp. 23-30, 2019.

[41] J. P. Lesage, "Spatial econometric panel data model specification: a Bayesian approach," Spatial Statistics, vol. 9, pp. 122-145, 2014.

[42] Y. Li, "R\&D knowledge spillover and regional innovation ability of Guangdong-Hong Kong-Macao Greater Bay Area-an empirical study based on multidimensional neighbourliness," Soft Science, vol. 33, no. 11, pp. 138-144, 2019.

[43] Y. Chen, C. Zhang, and Y. Wu, "Proximities and Knowledge Spillover in the Yangtze River Delta," Urban Development Studies, vol. 12, pp. 34-44, 2018.

[44] Y. Su and Y. Yu, "Spatial agglomeration of new energy industries on the performance of regional pollution control through spatial econometric analysis," Science of the Total Environment, vol. 704, Article ID 135261, 2020.

[45] J. Bai, S. Li, N. Wang, J. Shi, and X. Li, "Spatial spillover effect of new energy development on economic growth in developing areas of China-an empirical test based on the spatial dubin model," Sustainability, vol. 12, Article ID 3249, 2020.

[46] G. Liu, T. Yang, and X. Zhang, "Spatial econometric analysis of regional logistics impact on regional economy," Statistics and Decision, vol. 20, pp. 137-140, 2019.

[47] J. Li and S. Li, "Energy investment, economic growth and carbon emissions in China-empirical analysis based on spatial Durbin model," Energy Policy, vol. 140, Article ID 111425, 2020. 